\title{
Efficient Molecular Modelling of Butterfly-Shaped Hole Transport Materials With Remarkable Photovoltaic Properties For High-Performance Organic Solar Cells
}

\section{Muhammad Yasir Mehboob}

UO: University of Okara

Muhammad Adnan ( $\square$ adnan5750@gmail.com )

Chosun University https://orcid.org/0000-0001-9224-3824

Riaz Hussain

UO: University of Okara

Zobia Irshad

Chosun University

\section{Original Research}

Keywords: Hole Transport Materials, Organic solar cells, Power conversion efficiency, End-capped modifications, Butterfly shaped designing

Posted Date: February 12th, 2021

DOI: https://doi.org/10.21203/rs.3.rs-182560/v1

License: (c) (1) This work is licensed under a Creative Commons Attribution 4.0 International License.

Read Full License 


\section{Abstract}

Currently, organic solar cells (OSCs) with non-fullerene electron acceptors offer the highest efficiencies among all reported OSCs. To further improve the efficiencies and stabilities of fullerene-free organic solar cells, end-capped acceptor variations is built with strong electron withdrawing groups. In this report, we have theoretically calculated five new butterfly-shaped fullerene-free acceptors (FD1-FD6) by making endcapped modifications on reference molecule $(R)$ with the purpose to study the improvement in photophysical, opto-electronic, and photo-voltaic properties of newly designed molecules by employing density functional theory (DFT) and time dependent (TD-DFT). Besides, some properties like position of frontier molecular orbitals (FMOs), excitation and binding energy, hole-electron overlap, density of states, overlap density of states, molecular electrostatic potential, open circuit voltage, transition density matrix, and reorganizational energy of electron and hole are also considered and associated with experimentally synthesized reference compound. All calculated molecules displayed a good red-shifting with high charge mobility of electrons among low binding and excitation energies as opposed to reference molecule. Furthermore, all designed molecules (FD1-FD6) and the reference $\mathbf{R}$ shows narrow band-gap along-with great charge shifting capability. This theoretical framework proves that end-capped acceptors variation is a modest and effective strategy to accomplish the desirable opto-electronic properties. Therefore, FD1FD6 are suggested to experimentalist for out-looking future developments to fabricate highly efficient solar cells devices.

\section{Highlights}

1. Butterfly-shaped efficient hole transport molecules (FD1-FD6) are studied for high performance solar cells applications.

2. Significant lowering of energy gap with concomitant red shifting of the absorption spectra is achieved with end-group engineering.

3. These HTMs show lower binding energy and excellent electron and hole reorganizational energies.

4. All HTMs have remarkable optoelectronic properties compared to reference $\mathbf{R}$.

\section{Introduction}

Nowadays hybrid perovskite semiconductors are newly emerged semiconductor and are potentially focus on research in solar cells due to their high efficacious nature ${ }^{1}$. A semiconductor Spiro-OMETAD have high molecular weight, high cost and difficult to synthesize replace by low molecular weight hole transporting material (HTMs) by using recently computational research techniques to ensure the high yield ${ }^{2,3}$. For the synthesis of HTMs electron-donating moieties are being used like triphenylamines (TPA), diphenylamine's (DPA), as these had been already studied in Dye Sensitize Solar Cells (DSSC) ${ }^{1,3-6}$.

The benzothiadiazole (BT) group is a backbone of frequently used organic semiconductor ${ }^{7,8}$. Basically, it is a heterocyclic system with electron withdrawing nature can be used in transportation of charge carriers 
like negative charge and create hole. But in this case, we were not use it for this purpose. In this it acts as fluorophore. The structure bearing the BT-group has crystalline and planner structure and show conjugation in polymers, perovskite solar cells. Because it creates $\pi-\pi$ interaction ${ }^{9}$ with other moieties in polymers and solar cells. So through conjugation it must be used as a charge carrier ${ }^{10,11}$. Recently, C.R Seco and his co-workers had successfully elaborated and synthesized the novel hole transport materials for solar cell applications ${ }^{12}$. All synthesized molecules behaved well under given parameters but among all CSO1 ${ }^{12}$ disclosed high power conversion efficiency with narrow band gap. So, motivated from that report, our group decided to design and elaborate the photovoltaic properties of newly designed molecules by considering CS01 as reference molecule (R) ${ }^{12}$. In this work, CS01 is selected as reference molecule which have butterfly-shape, hence some chemical modifications were done by adding phenyl ring to make a binary connection between molecular structure of HTMs and device performance. On the behalf of quantum techniques used in CS01 we had done the quantum calculation of new designed molecule.

Motivated from these findings we presented six new novel butterfly-shaped HTMs (FD1-FD6). The BTgroup is used as core unit and covalently bonded with other ring system for making these molecules Donor-Accepter-Donor semiconductor. This D-A-D structure leading the transfer of charge to colored chromophore. And this BT-group tuned the highest occupied orbitals (HOMO) to achieve high value of Voc in solar cells. This lowest occupied orbital (LUMO) affected due to electron-withdrawing group and transportation of holes formed by the blocking of electrons. The examination of designed molecules is done by different quantum and chemical techniques. Also compare with reference molecule, the properties like photo-physical, opto-electronic properties and geometrical parameters, density of states, absorption maxima, excitation, binding and reorganizational energies of FD1-FD6 were exclusively studied. So finally, findings about newly designed molecules suggest that these can be used for the development of highly efficient solar cells.

\section{Computational Detail}

The calculations of newly designed solar cells have been done by using Gaussian 09 program and Gauss-View program visualized them. Firstly the reference molecule $\mathbf{R}$ optimized by using commands as B3LYP ${ }^{13}$, CAM-B3LYP ${ }^{14}$, MPW1PW91 ${ }^{15}$ and $\omega B$ B97XD ${ }^{16}$ levels in conjunction with 6-31G(d,p) ${ }^{17-20}$ basis set. By using above mentioned levels calculated the Time-dependent density functional theory (TDDFT) for reference compound to simulate the absorption spectrum. The absorbed maximum wavelength of reference compound is compared with reported experimental data. The absorption maximum $\left(\lambda_{\max }\right)$ value of Cam-B3LYP/6-31G $(d, p)$ level is nearest to experimental data ${ }^{12}$ as compare to other levels. At this level (Cam-B3LYP/6-31G(d,p) ) of theory the $\lambda_{\max }$ for reference R molecule and designed molecules ( FD1, FD2, FD3, FD4, FD5 and FD6) solvent phases. The analysis of TDM, dipole moment, reorganization energies, DOS calculations, FMOs and charge transfer of reference $\mathbf{R}$ and designed molecules have performed at above level (B3LYP/6-31G(d,p) ) of DFT. 
Reorganization energies has two sub categories:

(i) Internal reorganization energy $\left(\lambda_{\text {int }}\right)$ (ii) External reorganization energy $\left(\lambda_{\text {ext }}\right)$

The internal structure changes related to internal energy and external environment changes related to external energy. So we could have neglected the internal energy as can have neglected the external energy because it did not affect the current studies so much. For the calculation of reorganization energy below mentioned equations are helpful for electron $(\lambda e)$ and hole $\left(\lambda_{h}\right)^{21-23}$.

$\lambda e=\left[E_{0}{ }^{-}-E_{-}\right]+\left[E_{-}{ }^{0} E_{0}\right]$

$\lambda_{\mathrm{h}}=\left[E_{0}^{+}-E_{+}\right]+\left[E_{+}^{0}-E_{0}\right]$

The energies of neutral molecule are obtained by optimized anionic and cationic structures respectively.

\section{Result And Discussion}

\subsection{Selection of basis set}

In this contribution, the reference molecule CS01 (R) was initially optimized at four functionals like CamB3LYP, MPW1PW91, WB97XD, and B3LYP along with 6-31G(d,p) basis set. The DFT based observed absorption maxima in dichloromethane solvent is $486 \mathrm{~nm}$ (Cam-B3LYP/6-31G(d,p)), $625 \mathrm{~nm}$ (MPW1PW91/6-31G(d,p)), $475 \mathrm{~nm}(\omega B$ 97XD/6-31G(d,p)), $685 \mathrm{~nm}(B 3 \mathrm{LYP} / 6-31 \mathrm{G}(\mathrm{d}, \mathrm{p}))$, while experimental calculated absorption maxima $529 \mathrm{~nm}^{12}$ as shown in Figure 1. From above data and Figure 1, it is evidently concluded that CAM-B3LYP/6-31G(d,p) basis set disclosed best agreement with experimental data.

\subsection{Designing of molecules}

In this contribution, the reference molecule $\mathbf{C S 0 1}$ is taken as reference molecule (R) ${ }^{12}$. end-capped donor modifications of $\mathbf{R}$ (reference molecule) are made with $N, N$-dialkylaniline (FD1), triphenylamine (FD2), $N$, $\mathrm{N}$-diphenylnapthalein-1-amine (FD3), indoline (FD4), carbozole (FD5), and phenothiazine (FD6) as shown in Figure 2. After modifications, six new molecules are designed which were further analyzed by employing DFT calculations at Cam-B3LYP/6-31G(d,p) basis set.

\subsection{Alignment of Frontier molecular orbital}

Lowest unoccupied molecular orbital (LUMO) and highest occupied molecular orbital (HOMO) are known frontier molecular orbitals. In molecular orbital theory, the LUMO is considered as valence band and $\mathrm{HOMO}$ is considered as conduction and the gap between these two bands are known as band gap or in simple words it is known as HOMO-LUMO energy gap ${ }^{20,24-28}$. Energy gap is very important tool for analyzing the overall photovoltaic properties of a solar cell as it directly affected the rate of charge transfer between two molecular orbitals. So, the photovoltaic devices with narrow band gap offers high 
charge transfer between two molecular orbitals and vice versa. The optimized geometries of all studied molecules at Cam-B3LYP/6-31G(d,p) basis set is given in Figure 3.

Energies of both orbitals (HOMO and LUMO) also play vital role for demonstrating the overall efficiency of a photovoltaic device. The frontier molecular orbitals analysis is considered at B3LYP/6-31G(d,p) basis set of DFT. Table 1 describes the values of frontier molecular orbitals energies and HOMO-LUMO energy gap. Reference molecule disclosed HOMO and LUMO energy values as -5.60 , and $-0.80 \mathrm{eV}$. The designed molecules FD1-FD6 displayed HOMO values of $-5.69,-5.57,-5.71,-5.45,-5.45,-5.92$, and $-5.93 \mathrm{eV}$, and LUMO values of $-0.90,-0.83,-0.95,-0.74,-1.15$, and $-1.24 \mathrm{eV}$, respectively. The DFT based calculated band gap of reference molecule is $4.80 \mathrm{eV}$. Design molecules (FD1-FD6) displayed band gap of 4.79, 4.74, 4.76, $4.71,4.77$, and $4.69 \mathrm{eV}$, respectively. All designed butterfly-shaped molecules disclosed narrow band gap as compared to reference molecule. Narrow band-gap in designed molecules is might be due to addition of extra and efficient end-capped donor units in end-capped donor moieties. Narrowest energy band gap is observed in FD6 molecule which is due to phenothiazine unit. Second and third lowest energy band gap values are seen in FD4 and FD2 molecules which is probably due to indoline and triphenylamine units as shown in Figure 4. FD3 and FD5 molecules have very close values of band gap which is might be due to addition of extra functional group in donor moieties. The decreasing order of energy band gap of all studied molecules is: R> FD1> FD5> FD3> FD2> FD4> FD6.

From order and proceeding discussion, it is concluded that our designed molecules are superior than reference molecules, thus these molecules are fine aspirant for high performance solar cells.

Table 1: Energy of HOMO ( $\left.E_{\text {HOMO }}\right)$, energy of LUMO $\left(E_{\text {LUMO }}\right)$ and energy gap $\left(E_{g}\right)$ of all studied molecules

\begin{tabular}{|llll|}
\hline Molecules & E $_{\text {Hомо }}(\mathrm{eV})$ & $\mathrm{E}_{\text {LUMO }}(\mathrm{eV})$ & $\mathrm{E}_{\mathrm{g}}(\mathrm{eV})$ \\
\hline R (CS01) & -5.60 & -0.80 & 4.80 \\
\hline FD1 & -5.69 & -0.90 & 4.79 \\
\hline FD3 & -5.57 & -0.83 & 4.74 \\
\hline FD4 & -5.71 & -0.95 & 4.76 \\
\hline FD5 & -5.45 & -0.74 & 4.71 \\
\hline FD6 & -5.92 & -1.15 & 4.77 \\
\hline
\end{tabular}

\subsection{Density of states analysis}

Density of states (DOS) analysis has been done to unveil the position of frontier molecule orbitals $17,18,26,29-34$. This analysis is also useful for locating the HOMO and LUMO densities on a molecule. DOS 
analysis provides the evidences of efficient designing of hole transport materials by end-capped donor modifications.

Density of states analysis of all designed molecules is performed at Cam-B3LYP/6-31G(d,p) basis set and DOS plots are given in Figure 5. From figure it is came to know that HOMO density in molecules are present on donor part. In reference and designed molecules same distribution is observed. In designed molecules end-capped efficient donor units donate electron density and core unit being acceptor in nature accept the electron density. The presence of LUMO density on central acceptor unit supportive of our notion. So, from above analysis it is concluded that all designed molecules are efficient donor molecules and donate the electron density efficiently and presence of same distribution pattern of electron density in reference and designed molecules suggested that our end-capped donor modification is a fine approach for development of high performance solar cells.

\subsection{Photovoltaic Properties}

Excitation energy, molecular oscillating strength, concern HOMO to LUMO molecular assignment and absorption maxima in solvent phase are known as photovoltaic properties and behavior of a solar cell ${ }^{35}$. All these properties are comprehensively studied and analyzed by employing time dependent-density functional theory at Cam-B3LYP method with conjunction of $6-31 \mathrm{G}(\mathrm{d}, \mathrm{p})$ basis set.

The absorption maxima of all studied molecules is estimated in dichloromethane solvent as shown in Table 2. The experimental recorded absorption maxima were $529 \mathrm{~nm}$, while DFT based observed absorption maxima is $486.01 \mathrm{~nm}$. Usually, red-shifting in absorption spectrum offer high and intense absorption in particular region of light which in return enhances the overall power conversion efficiency of a solar cell. The designed butterfly-shaped donor molecules expressed large red-shifting in absorption spectrum which might be due to addition of different end-capped donor units in end-capped donor moieties of reference molecule. The absorption maxima values of designed molecule FD1 is $506.33 \mathrm{~nm}$, similarly other designed molecules have absorption maxima values of $528.21 \mathrm{~nm}$ (FD2), $530.93 \mathrm{~nm}$ (FD3), 551.44 nm (FD4), $549.01 \mathrm{~nm}$ (FD5), and $568.65 \mathrm{~nm}$ (FD6), respectively. All butterfly-shaped designed molecules have red-shifted absorption spectrum as compared to reference molecule. Large redshifting in absorption spectrum is seen in FD6 followed by FD4, which is might be due to phenothiazine and indoline end-capped units. Similarly, FD5, FD3, FD2 and FD1 also exhibited red-shifting in absorption spectrum which is probably due to carbazole, $N, N$-diphenylnapthalein-1-amine, triphenylamine, and $N, N$ dialkylaniline end-capped units. In short, all designed molecules displayed red-shifting in absorption spectrum which mean that these designed molecules are better hole transport materials as compared to reference molecule for solar cells.

Table 2. Absorption maxima (experimental and DFT based), excitation energy, oscillating strength and major concerned molecular orbitals assignments 


\begin{tabular}{|llllll|}
\hline Molecule & DFT. $\lambda_{\max }$ & Exp. $\boldsymbol{\lambda}_{\max }$ & $\mathrm{E}_{\mathrm{x}}(\mathrm{eV})$ & $\boldsymbol{f}$ & Assignment \\
\hline R (CS01) & 486.01 & 529 & 2.01 & 2.17 & HOMO $\rightarrow$ LUMO (99\%) \\
\hline FD1 & 506.33 & - & 1.99 & 2.37 & HOMO $\rightarrow$ LUMO (99\%) \\
\hline FD2 & 528.21 & - & 1.81 & 2.92 & HOMO $\rightarrow$ LUMO (99\%) \\
\hline FD3 & 530.93 & - & 1.80 & 3.19 & HOMO $\rightarrow$ LUMO (99\%) \\
\hline FD4 & 551.44 & - & 1.74 & 3.26 & HOMO $\rightarrow$ LUMO (98\%) \\
\hline FD5 & 549.01 & - & 1.76 & 3.15 & HOMO $\rightarrow$ LUMO (99\%) \\
\hline FD6 & 568.65 & - & 1.69 & 3.35 & HOMO $\rightarrow$ LUMO (99\%) \\
\hline
\end{tabular}

Excitation energy is yet another tool which measure the efficiency of a solar cell. The lower value of excitation energy offers high power conversion efficiency and rapid transportation of charge density from excited HOMO to excited LUMO in a solar cell. Therefore, excitation energy analysis of all designed molecules is estimated at Cam-B3LYP/6-31G(d,p) basis set. According to Table 2, all designed molecules disclosed lower values of excitation energy as compared to reference molecule which is might be due to addition of efficient donor moieties in the end-capped of all donor molecules. The decreasing order of excitation energy is: $\left[R\left(E_{x}=2.01 \mathrm{eV}\right)\right]>\left[F D 1\left(E_{x}=1.99 \mathrm{eV}\right)\right]>\left[F D 2\left(E_{x}=1.81 \mathrm{eV}\right)\right]>\left[F D 3\left(E_{x}=1.80 \mathrm{eV}\right)\right]>[$ FD5 $\left.\left(E_{x}=1.76 \mathrm{eV}\right)\right]>\left[F D 4\left(E_{x}=1.74 \mathrm{eV}\right)\right]>\left[F D 6\left(E_{x}=1.69 \mathrm{eV}\right)\right]$. From discussion, it is suggested that designed molecules are better candidates for solar cell applications as compared to reference molecule.

Simulated UV graph of all studied molecules is also considered in solvent phase and displayed in Figure 6. From Figure 6, it is easily located that all designed molecules have great red-shifting in absorption spectrum as compared to reference molecule. So, results of photovoltaic parameters suggested that designed butterfly-shaped donor molecules are efficient aspirants for solar cell applications.

\subsection{Reorganizational Energy}

Reorganizational energy is one of the important factor which decided the overall efficiency of a solar cell. Charge mobility and reorganizational energy have inverse relationship with each other, i.e. lower value of reorganizational energy allows high charge mobilities and vice versa. Low reorganizational energy of a solar cell offers high hole and electron mobility in a solar cell. High hole and electron transportability of a solar cell also provides high power conversion efficiency in a solar cell.

The reorganizational energy of hole and electro is considered at Cam-B3LYP/6-31G(d,p) basis set. The reorganizational energy of hole of reference molecule is 0.0171 , while designed molecules have reorganizational energy of hole of 0.0168 (FD1), 0.0168 (FD2), 0.0165 (FD3), 0.0166 (FD4), 0.0158 (FD5), and 0.0149 (FD6). All designed molecules displayed low values of hole reorganizational energy as shown in Figure 7. Lowest value is noted for FD6 molecule which is due to phenothiazine unit that is present in end-capped moiety of FD6. Second and third lowest value of hole reorganizational energy is seen FD5 
and FD3 molecules which is might be due to carbazole and $N, N$-diphenylnapthalein-1-amine end-capped units. Overall, it is observed that designed molecules are better hole transport materials for solar cell applications.

Reorganizational energy of electron is also estimated at Cam-B3LYP/6-31G(d,p) basis set. The calculated reorganizational energy of electron of reference molecules is 0.0198 . The reorganizational energy of electron of designed molecules are $0.0206,0.0221,0.0208,0.0201,0.0211$, and 0.199 for FD1-FD6, respectively. All designed molecules have comparable values of reorganizational energy of electron as compared to reference molecule. Among designed molecules, FD6 expressed highest electron mobility and lowest reorganizational energy of electron which is might be due to addition of extra functional group in end-capped acceptor moiety. Overall, from discussion, it is evidently proved that all designed molecules are fine candidates for solar cell applications, thus designed are recommended for development of high performance solar cells.

Table 3. Reorganizational energy of hole and electron of all studied molecules at CAM-B3LYP/6-31G(d,p) basis set of DFT.

\begin{tabular}{|lll|}
\hline Molecules & $\lambda_{\mathrm{e}}$ & $\lambda_{\mathrm{h}}$ \\
\hline R (CS01) & 0.0198 & 0.0171 \\
\hline FD1 & 0.0206 & 0.0168 \\
\hline FD2 & 0.0221 & 0.0168 \\
\hline FD3 & 0.0208 & 0.0165 \\
\hline FD4 & 0.0201 & 0.0166 \\
\hline FD5 & 0.0211 & 0.0158 \\
\hline FD6 & 0.0199 & 0.0149 \\
\hline
\end{tabular}

\subsection{Open Circuit Voltage}

The total current drawn for any optical device is known as open circuit voltage. Open circuit voltage depends on saturated and degenerated current of a photovoltaic device. Open circuit voltage measures the power conversion efficiency of a solar cell. Open circuit voltage $\left(V_{o c}\right)$ also affects the current charge density of a solar cell. Open circuit voltage in the case of charge density donor molecule, is calculated by lying the HOMO of donor molecules and LUMO of a acceptor polymer.

Our reference and designed molecules (FD1-FD6) are donor in nature with good charge donating aptitude. So, we use the HOMO orbital of all these molecules that are lying with LUMO of acceptor polymer which is $\mathrm{PC}_{61} \mathbf{B M}$. $\mathrm{PC}_{61} \mathrm{BM}$ is well known and very famous acceptor polymer and mostly used for solar cell applications. Figure 8, expressed the open circuit voltage of all molecules with respect to $\mathrm{HOMO}_{\text {Donor }}{ }^{-}$ 


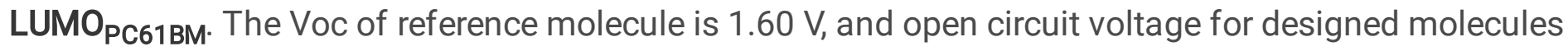
FD1-FD6 is 1.69, 1,57, 1.71, 1.43, 1.92, and $1.93 \mathrm{~V}$ as shown in Figure 8. All designed molecules (except FD2, and FD4) have higher value of open circuit voltage. The higher values of open circuit voltage suggested that designed molecules are efficient candidates for solar cell applications. Among designed molecules, FD6 molecule disclosed highest open circuit voltage which is due to phenothiazine endcapped unit. Second and third highest values of open circuit voltage is seen in FD5 and FD3 molecules which is probably due to carbazole and $N, N$-diphenyInapthalein-1-amine end-capped units. Similarly, FD1 due to $N, N$-dialkylaniline end-capped unit disclosed high open circuit voltage as compared to reference molecule as shown in Figure 8. So, from above discussion we concluded that designed molecules especially FD6 and FD5 are more efficient candidates for solar cell applications.

Orbitals position donor molecules and acceptor polymer is very important for charge shifting ${ }^{36}$. It is suggested that low lying LUMO of acceptor polymer and high level of HOMO od donor molecules offer high charge shifting in donor: acceptor blend. In current report, same condition is seen which suggested that designed donor molecules are efficient molecules that contributes much in overall charge transfer from donor to acceptor molecule as shown in Figure 9.

\subsection{Transition density matrix and binding energy analysis}

Transition density matrix (TDM) were carried out to investigate the electronic transition processes occurred in photovoltaic materials. TDM study of the designed materials provides a useful insight about electronic transition and has a characteristic to produce three dimensional (3D) maps which corresponds to the linked electron-hole pairs. These instigations also provide information about the delocalization and coherence lengths of the materials. TDM analysis also useful to estimate the nature of transition appeared during $S_{1}$ emission state. Mainly, we can employ these calculations to understand the charge transfer excitation behavior of the molecules. The calculated TDM plots of all the designed and the reference molecule $\mathrm{R}$ are shown in Figure 10.

Table 4: Binding energy, first principle excitation energy and HOMO-LUMO energy gap of all studied HTMs

\begin{tabular}{|llll|}
\hline Molecules & $E_{H-L}$ & $E_{o p t}$ & $E_{b}$ \\
\hline R (CS01) & 4.80 & 2.01 & 2.79 \\
\hline FD1 & 4.79 & 2.02 & 2.77 \\
\hline FD2 & 4.74 & 1.99 & 2.75 \\
\hline FD3 & 4.76 & 1.97 & 2.79 \\
\hline FD4 & 4.71 & 2.00 & 2.71 \\
\hline FD5 & 4.77 & 2.09 & 2.68 \\
\hline FD6 & 4.69 & 2.22 & 2.47 \\
\hline
\end{tabular}


In order to understand this phenomenon, we have divided the molecule into three different parts; donor as core unit (D), donor part (D) while terminal acceptors as (A), respectively. We realized that the end-capped donors as well as bridged part are covered with electronic charge mobility of the corresponding material. The presence of various electronic charge associations in reference molecule $\mathbf{R}$ and in FD1-FD6 designed systems revealed that charge transformation occurred from donor to bridged part of the molecule with any hindrance. The other important parameter that is related to the evaluation of proficiency, excited splitting potential and the related electronic properties is binding energy. The columbic forces present in the molecule was responsible for the interaction of hole and electrons which is directly influenced by $E_{b}$ and inversely proportional to excitation segregation potential at excited state. Hereafter, any increment in $E_{b}$ can directly influence the columbic force present in between the electron and holes. The calculation of the related $\mathrm{E}_{\mathrm{b}}$ can be done by the following equation.

$E_{b}=E_{H-L}-E_{o p t}$

In this equation, $\mathrm{E}_{\mathrm{H}-\mathrm{L}}$ corresponds to the difference of $\mathrm{HOMO}$ and $\mathrm{LUMO}$, while, $\mathrm{E}_{\mathrm{opt}}$ relates to the amount of energy required for first excitation $\left(S_{0}-S_{1}\right)$ known as singlet excitation. As we see Table 4, FD6 has the ability to produce extra charges that can dissociate easily and that's why we can assume that it would be more helpful to improve the photocurrent density of the devices.

Figure 11, showed the calculated Eb, Eopt and Eh-L spectrum. It is interesting that all the designed materials exhibited low Eb values which provides an evidence of our efficient designing of materials. The corresponding Eb, EH-L and Eopt values have been shown in Table 4. All of the calculated values of the designed materials lie closer to the reference molecule R. Among these, FD6 showed the lowest possible Eb value which is due to attachment of an efficient end-capped unit. The other designed materials FD1 to FD5 have also quite lower Eb values as compared with reference R. Hence, due to this study we can estimate the efficient charge transformation behavior of the molecules which will ultimately help to boost the $J_{s c}$ values of these materials. Based on these investigations, we can claim that these designed materials are best fitted for solar cells applications.

\subsection{Molecular Electrostatic Potential (MEP) analysis}

Figure 12 shows the computational characterization of MEP analysis of all the designed (FD1-FD6) and the reference $\mathbf{R}$. These MEP investigations was done by employing well known Cam-B3LYP/6-31G(d,p) level of theory. The purpose behind these investigations is to understand the behavior of various charge sites present in the molecule. These calculations are done using iso-surface value of $0.02 \mathrm{e} / \AA^{3}$ for all the newly designed (FD1-FD6) and also for the reference molecule R. In these outcomes, we realized various cloud densities and every cloud color density is related to specific property of the molecule. For instance, blue color showed presence of positive charge accumulation, red for negative and green color represent the most possible potential area of the molecule i.e. neutral region among all designed (FD1-FD6) and reference molecule $\mathbf{R}$. 
Interestingly, we realized almost similar charge sites over all the designed molecules especially on FD1FD4 as compared with reference R. The designed materials FD5 and FD6 shows the specific uniform distribution of charges which spreads on the whole molecule equally. Therefore, with these results we can predict our efficient end-capped designing of the molecules for photovoltaic applications. As shown in figure 12, more charge density spreads over FD6, indicating its superiority over others designed materials (FD1-FD5) for the most efficient charge transfer reactions.

\subsection{Study of Complex FD6/PC 61 BM}

We have also performed some specific calculations related to charge transfer analysis (CTA) for all the newly designed as well as for reference molecule R. For this purpose, we have selected one best working designed material (FD6) for these investigations and makes its complex with the well-known polymer acceptor $\mathrm{PC}_{61} \mathrm{BM}$. The polymer acceptor $\mathrm{PC}_{61} \mathrm{BM}$ and the D-A units $\mathrm{FD6}: \mathrm{PC}_{61} \mathrm{BM}$ were initially optimized at Cam-B3LYP/6-31G(d,p) level of theory. The selection of donor FD6 was done due its outstanding hole mobility and charge transfer abilities as compared with other designed materials (FD1-FD5), respectively. The optimized geometries of newly designed $\mathrm{FD} 6$ and polymer acceptor $\mathrm{PC}_{61} \mathrm{BM}$ revealed that both of the materials are oriented parallel to each other, as shown in figure 13. The FD6: $\mathbf{P C}_{61} \mathbf{B M}$ formed a unique orientation where $\mathrm{PC}_{61} \mathrm{BM}$ came parallel on that side of $\mathrm{FD} 6$ where there is a chance for maximum charge transformation can happen in between these D-A interfaces.

In addition, we have also optimized $\mathrm{FD} 6$ and $\mathrm{PC}_{61} \mathrm{BM}$ units individually to investigate their $\mathrm{HOMO}$ and LUMO levels, as shown in figure 13. For this, we have also used the same methodology (Cam-B3LYP/6$31 \mathrm{G}(\mathrm{d}, \mathrm{p})$ ) as we did for other designed materials and the reference $\mathbf{R}$. The HOMO-LUMO distribution patterns are shown in figure 14. With these studied, we realized that the HOMO density resides over donor part i.e. FD6, while, LUMO density spreads over $\mathrm{PC}_{61} \mathrm{BM}$. At HOMO-LUMO interface, we suspect that charge transformation occurred from $\mathrm{D}$ to $\mathrm{A}$ interface, ensuring clear understanding for charge density transformation between two oppositely charge moieties.

\section{Conclusion}

In this work, we designed butterfly shaped non-fullerene acceptors for solar cells applications. Remarkably, after successful theoretical optimizations, all the newly designed (FD1-FD6) have showed quite interesting photo-physical, optoelectronic, and photovoltaic properties. We efficiently designed these new FD1-FD6 molecules by end-capped mutation of reference material R. The HOMO-LUMO energy-gap contractions are quite narrower in FD1-FD6 designed molecules $\left(E_{g}=1.69-1.99 \mathrm{eV}\right)$ as compare to reference compound $R\left(E_{g}=2.01 \mathrm{eV}\right)$, which are quite desirable and attractive. This end-capped modification strategy revealed our efficient designing and explore the ways how we can tune the bandgaps of the materials efficiently and investigate their photo-physical and opto-electronic properties theoretically first instead after synthesizing them. The distribution pattern of HOMO and LUMO depends upon the charge density and overlap density of states. High absorption efficiency was achieved by 
observing highly red- shifting behavior in absorption spectrum, sideways with maximum charge shifting from excited HOMO to LUMO. All the theoretically optimized molecules (FD1-FD6) revealed suitable redshifting absorption behavior as opposed to reference material R. Besides, the resultant molecule (FD6) has minimal excitation and binding energy which might have ability to produce high current density. Usually, low energies of electron and hole are responsible for high charge mobilities, therefore, our designed molecules (FD1-FD6) displayed high electron mobilities as opposed to reference material R. Open circuit voltages and complicated study of $\mathrm{PC}_{61} \mathrm{BM}: \mathrm{FD} 6$ complex is also achieved by realizing great charge shifting from HOMO to LUMO molecular orbitals. Transition density matrix and hole-electron overlap study of all calculated molecules (FD1-FD6) divulge the position of charges in a molecule. Briefly, the fallouts of all analysis show that our designed compounds FD1-FD6 have high photo-voltaic and opto-electronic properties than reference material R. That's why, the conceptualized fullerene-free molecules should be aimed for synthesis of high-performance organic solar cells.

\section{Declarations}

Acknowledgement: We are highly thankful to Prof, Jae Kwan Lee from Chosun University, Republic of Korea for his useful guidance about the project and to provide his state-of-the-art lab facilities.

\section{Conflict of interest}

All authors declared no conflicts of interest.

\section{Associated Content}

Optimized Cartesian coordinates of all studied molecules ( $R$ and FD1-FD6) are available in supporting information file.

\section{References}

1. Ramasamy S, Gopi P, Raju S, Kathavarayan S (2018) Comparative Analysis of Fluorene and Carbazole Fused Triphenylamine Sensitizer Donor Units with New Anchoring Mode in Dye-Sensitized Solar Cells. React Funct Polym 122:123-130.

https://doi.org/10.1016/j.reactfunctpolym.2017.11.013

2. Giannopoulos P, Raptis D, Theodosiou K, Andreopoulou AK, Anastasopoulos C, Dokouzis A, Leftheriotis G, Lianos P, Kallitsis JK (2018) Organic Dyes End-Capped with Perfluorophenyl Anchors: Synthesis, Electrochemical Properties and Assessment of Sensitization Capacity of Titania Photoanodes. Dye Pigment 148:167-179. https://doi.org/10.1016/j.dyepig.2017.09.007

3. Sun H, Li P, Liu D, Wang T, Li W, Hu W, Wang L, Zhou X (2019) Tuning Photophysical Properties via Alkoxyl Groups in Charge-Separated Triphenylamine Sensitizers for Dye-Sensitized Solar Cells. J Photochem Photobiol A Chem 368:233-241. https://doi.org/10.1016/j.jphotochem.2018.09.033 
4. Agarwala P, Kabra DA Review on Triphenylamine (TPA) Based Organic Hole Transport Materials (HTMs) for Dye Sensitized Solar Cells (DSSCs) and Perovskite Solar Cells (PSCs): Evolution and Molecular Engineering. J. Mater. Chem. A 2017, 5 (4), 1348-1373.

https://doi.org/10.1039/C6TA08449D

5. Pham HD, Jain SM, Li M, Manzhos S, Feron K, Pitchaimuthu S, Liu Z, Motta N, Wang H, Durrant JR, Sonar P (2019) Dopant-Free Novel Hole-Transporting Materials Based on Quinacridone Dye for HighPerformance and Humidity-Stable Mesoporous Perovskite Solar Cells. J Mater Chem A 7(10):53155323. https://doi.org/10.1039/C8TA11361K

6. Pham HD, Hu H, Wong F-L, Lee C-S, Chen W-C, Feron K, Manzhos S, Wang H, Motta N, Lam YM, Sonar P (2018) Acene-Based Organic Semiconductors for Organic Light-Emitting Diodes and Perovskite Solar Cells. J Mater Chem C 6(33):9017-9029. https://doi.org/10.1039/C8TC01956H

7. Balasankar T, Gopalakrishnan M, Nagarajan S (2005) Synthesis and Antibacterial Activity of Some 5(4-Biphenylyl)-7-Aryl[3,4-d] [1,2,3]-Benzothiadiazoles. Eur J Med Chem 40(7):728-731. https://doi.org/10.1016/j.ejmech.2005.01.005

8. Balasankar T, Gopalakrishnan M, Nagarajan S (2007) Synthesis and Antibacterial Activity of Some 5(4-Biphenylyl)-7-Aryl[3,4-d]-1,2,3-Benzoselenadiazoles. J Enzyme Inhib Med Chem 22(2):171-175. https://doi.org/10.1080/14756360601051365

9. Neto BAD, Lapis AAM, da Silva Júnior EN, Dupont J 2,1,3-Benzothiadiazole and Derivatives: Synthesis, Properties, Reactions, and Applications in Light Technology of Small Molecules. European J. Org. Chem. 2013, 2013 (2), 228-255. https://doi.org/10.1002/ejoc.201201161

10. Kumar NS, Ibrahim AA, Dhar A, Vekariya RL (2019) Optoelectrical Characterization of Different Fabricated Donor Substituted Benzothiazole Based Sensitizers for Efficient DSSCs. J Photochem Photobiol A Chem 372:35-41. https://doi.org/10.1016/j.jphotochem.2018.12.004

11. Revoju S, Biswas S, Eliasson B, Sharma GD (2019) Phenothiazine-Based Small Molecules for Bulk Heterojunction Organic Solar Cells; Variation of Side-Chain Polarity and Length of Conjugated System. Org Electron 65:232-242. https://doi.org/10.1016/j.orgel.2018.11.024

12. Rodríguez-Seco C, Méndez M, Roldán-Carmona C, Cabau L, Asiri AM, Nazeeruddin MK, Palomares E (2020) Benzothiadiazole Aryl-Amine Based Materials as Efficient Hole Carriers in Perovskite Solar Cells. ACS Appl Mater Interfaces 12(29):32712-32718. https://doi.org/10.1021/acsami.0c07586

13. Civalleri B, Zicovich-Wilson CM, Valenzano L, Ugliengo P (2008) B3LYP Augmented with an Empirical Dispersion Term (B3LYP-D*) as Applied to Molecular Crystals. CrystEngComm 10(4):405-410. https://doi.org/10.1039/B715018K

14. Yanai T, Tew DP, Handy NC (2004) A New Hybrid Exchange-Correlation Functional Using the Coulomb-Attenuating Method (CAM-B3LYP). Chem Phys Lett 393(1-3):51-57. https://doi.org/10.1016/j.cplett.2004.06.011

15. Adamo C, Barone V (1998) Exchange Functionals with Improved Long-Range Behavior and Adiabatic Connection Methods without Adjustable Parameters: The MPW and MPW1PW Models. J Chem Phys 108(2):664-675. https://doi.org/10.1063/1.475428 
16. Chai J-D, Head-Gordon M (2008) Long-Range Corrected Hybrid Density Functionals with Damped Atom-Atom Dispersion Corrections. Phys Chem Chem Phys 10(44):6615.

https://doi.org/10.1039/b810189b

17. Khan MU, Mehboob MY, Hussain R, Fatima R, Tahir MS, Khalid M, Braga AAC (2020) Molecular Designing of High-performance 3D Star-shaped Electron Acceptors Containing a Truxene Core for Nonfullerene Organic Solar Cells. J Phys Org Chem. https://doi.org/10.1002/poc.4119

18. Bilal Ahmed Siddique M, Hussain R, Ali Siddique S, Yasir Mehboob M, Irshad Z, Iqbal J, Adnan M (2020) Designing Triphenylamine-Configured Donor Materials with Promising Photovoltaic Properties for Highly Efficient Organic Solar Cells. ChemistrySelect 5(25):7358-7369. https://doi.org/10.1002/slct.202001989

19. Mehboob MY, Khan MU, Hussain R, Fatima R, Irshad Z, Adnan M (2020) Designing of Near-Infrared Sensitive Asymmetric Small Molecular Donors for High-Efficiency Organic Solar Cells. J Theor Comput Chem 19(08):2050034. https://doi.org/10.1142/S0219633620500340

20. Hussain R, Hassan F, Khan MU, Mehboob MY, Fatima R, Khalid M, Mahmood K, Tariq CJ, Akhtar MN (2020) Molecular Engineering of A-D-C-D-A Configured Small Molecular Acceptors (SMAs) with Promising Photovoltaic Properties for High-Efficiency Fullerene-Free Organic Solar Cells. Opt Quantum Electron 52(8):364. https://doi.org/10.1007/s11082-020-02482-7

21. Khan, M. U.; Mehboob, M. Y.; Hussain, R.; Afzal, Z.; Khalid, M.; Adnan, M. Designing Spirobifullerene Core Based Three-dimensional Cross Shape Acceptor Materials with Promising Photovoltaic Properties for < scp > high-efficiency</Scp > Organic Solar Cells. Int. J. Quantum Chem. 2020. https://doi.org/10.1002/qua.26377.

22. Mehboob MY, Khan MU, Hussain R, Ayub K, Sattar A, Ahmad MK, Irshad Z, Saira; Adnan M Designing of Benzodithiophene Core-Based Small Molecular Acceptors for Efficient Non-Fullerene Organic Solar Cells. Spectrochim Acta Part A Mol Biomol Spectrosc 2020, 118873. https://doi.org/10.1016/j.saa.2020.118873

23. Mehboob MY, Hussain R, Khan MU, Adnan M, Umar A, Alvi MU, Ahmed M, Khalid M, Iqbal J, Akhtar MN, Zafar F, Shahi MN (2020) Designing N-Phenylaniline-Triazol Configured Donor Materials with Promising Optoelectronic Properties for High-Efficiency Solar Cells. Comput Theor Chem 1186:112908. https://doi.org/10.1016/j.comptc.2020.112908

24. Khan MU, Hussain R, Mehboob MY, Khalid M, Ehsan MA, Rehman A, Janjua MRSA (2021) First Theoretical Framework of Z-Shaped Acceptor Materials with Fused-Chrysene Core for High Performance Organic Solar Cells. Spectrochim Acta Part A Mol Biomol Spectrosc 245:118938. https://doi.org/10.1016/j.saa.2020.118938

25. Khan MU, Hussain R, Yasir Mehboob M, Khalid M, Shafiq Z, Aslam M, Al-Saadi AA, Jamil S, Janjua MRS (2020) A. In Silico Modeling of New "Y-Series"-Based Near-Infrared Sensitive Non-Fullerene Acceptors for Efficient Organic Solar Cells. ACS Omega 5(37):24125-24137. https://doi.org/10.1021/acsomega.0c03796 
26. Siddique SA, Siddique MBA, Hussain R, Liu X, Mehboob MY, Irshad Z, Adnan M (2020) Efficient Tuning of Triphenylamine-Based Donor Materials for High-Efficiency Organic Solar Cells. Comput Theor Chem 1191:113045. https://doi.org/10.1016/j.comptc.2020.113045

27. Ahmed M, Imran M, Muddassar M, Hussain R, Khan MU, Ahmad S, Mehboob MY, Ashfaq S (2020) Benzenesulfonohydrazides Inhibiting Urease: Design, Synthesis, Their in Vitro and in Silico Studies. J Mol Struct 1220:128740. https://doi.org/10.1016/j.molstruc.2020.128740

28. Hussain S, Shahid Chatha SA, Hussain Al, Hussain R, Mehboob MY, Gulzar T, Mansha A, Shahzad N, Ayub K (2020) Designing Novel Zn-Decorated Inorganic B 12 P 12 Nanoclusters with Promising Electronic Properties: A Step Forward toward Efficient CO 2 Sensing Materials. ACS Omega 5(25):15547-15556. https://doi.org/10.1021/acsomega.0c01686

29. Adnan M, Iqbal J, BiBi S, Hussain R, Akhtar MN, Rashid MA, Eliasson B, Ayub K Fine Tuning the Optoelectronic Properties of Triphenylamine Based Donor Molecules for Organic Solar Cells. Zeitschrift für Phys Chemie 2017, 231 (6). https://doi.org/10.1515/zpch-2016-0790

30. Hussain R, Khan MU, Mehboob MY, Khalid M, lqbal J, Ayub K, Adnan M, Ahmed M, Atiq K, Mahmood K (2020) Enhancement in Photovoltaic Properties of N, N -diethylaniline Based Donor Materials by Bridging Core Modifications for Efficient Solar Cells. ChemistrySelect 5(17):5022-5034. https://doi.org/10.1002/slct.202000096

31. Hussain R, Imran M, Mehboob MY, Ali M, Hussain R, Khan MU, Ayub K, Yawer MA, Saleem M, Irfan A (2020) Exploration of Adsorption Behavior, Electronic Nature and NLO Response of Hydrogen Adsorbed Alkali Metals (Li, Na and K) Encapsulated Al12N12 Nanocages. J Theor Comput Chem 19(08):2050031. https://doi.org/10.1142/S0219633620500315

32. Hussain R, Saeed M, Mehboob MY, Khan SU, Usman Khan M, Adnan M, Ahmed M, Iqbal J, Ayub K (2020) Density Functional Theory Study of Palladium Cluster Adsorption on a Graphene Support. RSC Adv 10(35):20595-20607. https://doi.org/10.1039/D0RA01059F

33. Hussain S, Chatha SAS, Hussain Al, Hussain R, Mehboob MY, Muhammad S, Ahmad Z, Ayub K ZincDoped Boron Phosphide Nanocluster as Efficient Sensor for SO 2. J. Chem. 2020, 2020, 1-12. https://doi.org/10.1155/2020/2629596

34. Hussain S, Hussain R, Mehboob MY, Chatha SAS, Hussain Al, Umar A, Khan MU, Ahmed M, Adnan M, Ayub K (2020) Adsorption of Phosgene Gas on Pristine and Copper-Decorated B 12 N 12 Nanocages: A Comparative DFT Study. ACS Omega 5(13):7641-7650.

https://doi.org/10.1021/acsomega.0c00507

35. Hussain R, Mehboob MY, Khan MU, Khalid M, Irshad Z, Fatima R, Anwar A, Nawab S, Adnan M (2020) Efficient Designing of Triphenylamine-Based Hole Transport Materials with Outstanding Photovoltaic Characteristics for Organic Solar Cells. J Mater Sci. https://doi.org/10.1007/s10853-020-05567-6

36. Younas F, Mehboob MY, Ayub K, Hussain R, Umar A, Khan MU, Irshad Z, Adnan M Efficient Cu Decorated Inorganic B 12 P 12 Nanoclusters for Sensing Toxic COCl 2 Gas: A Detailed DFT Study. J Comput Biophys Chem 2020, 2150006. https://doi.org/10.1142/S273741652150006X 
Figures

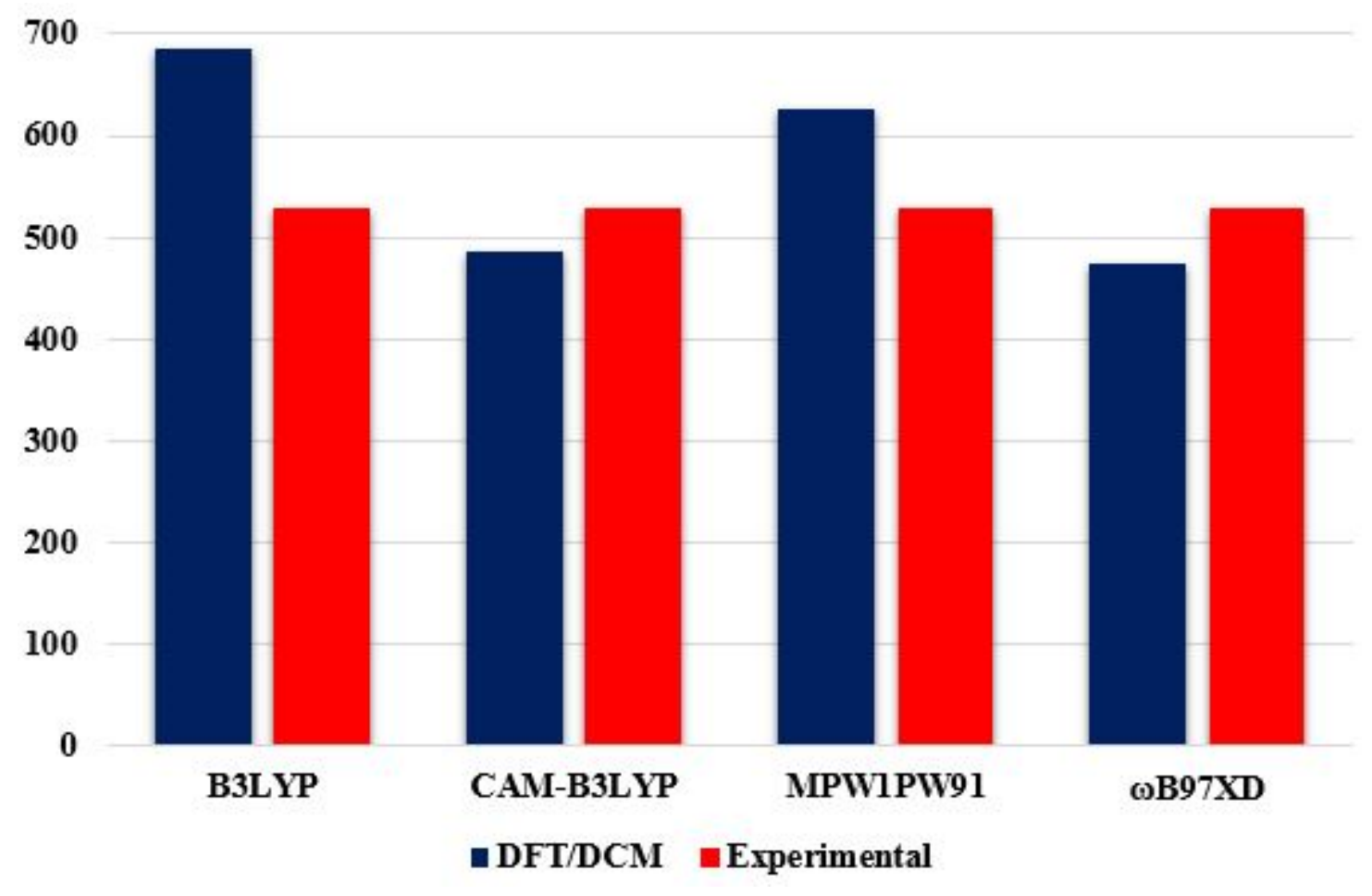

Figure 1

Bar chart of absorption maxima at four functionals with $6-31 \mathrm{G}(\mathrm{d}, \mathrm{p})$ basis set in dichloromethane solvent. 


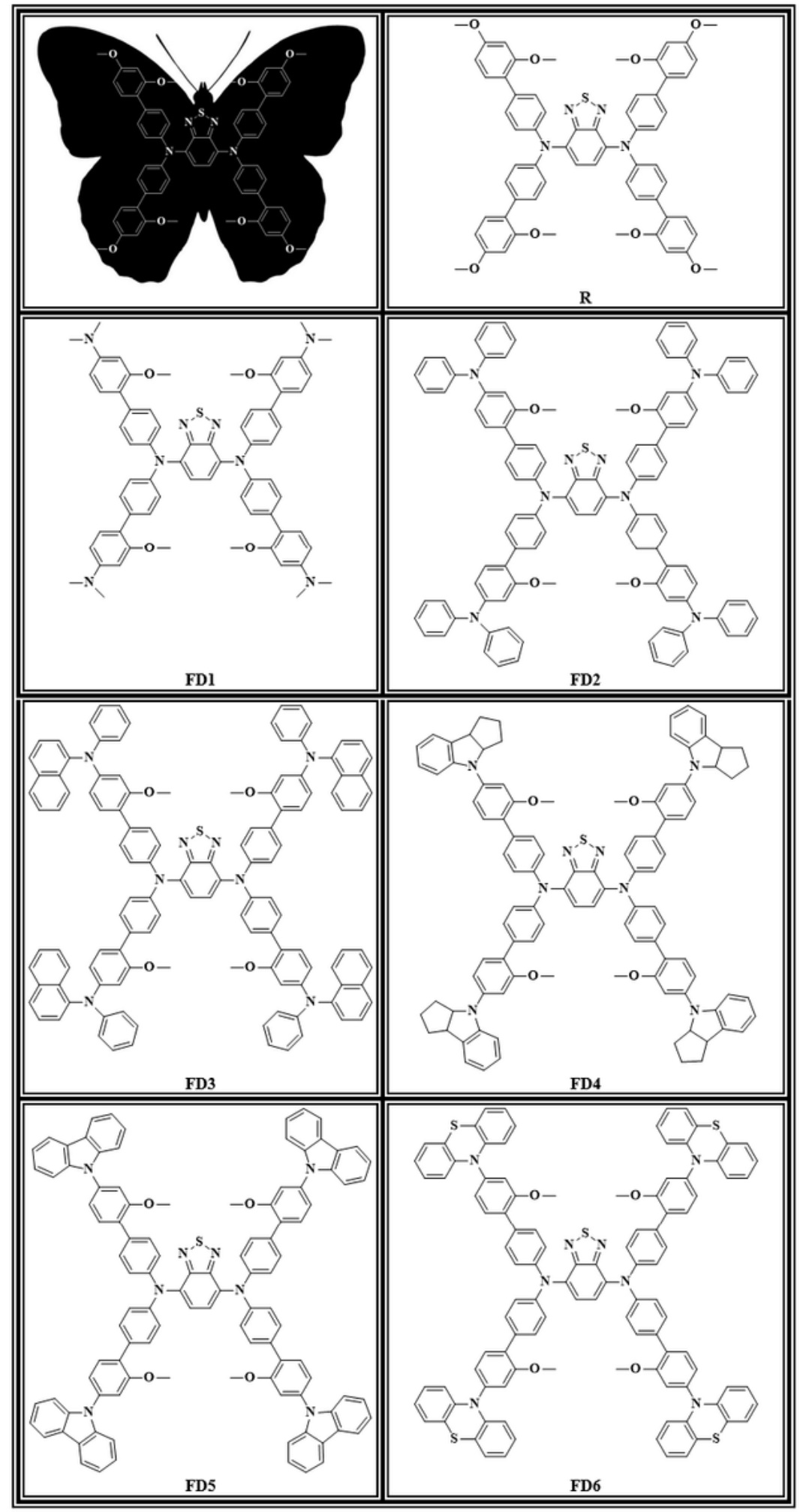

Figure 2

End-capped engineering of reference molecule with end-capped donor and molecular structure of all designed molecules 


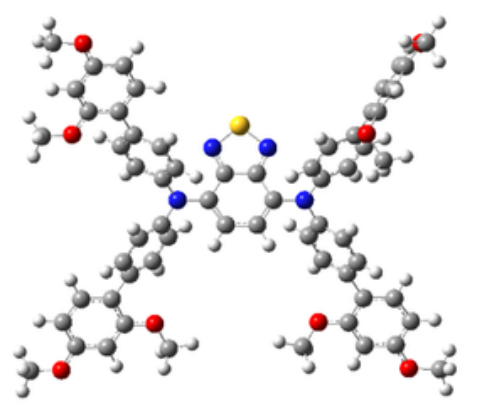

$\mathbf{R}$

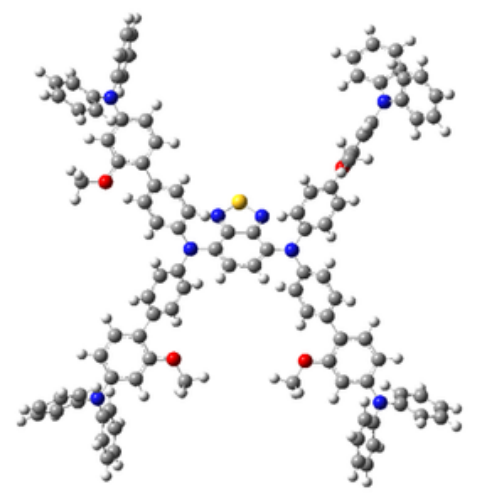

FD2

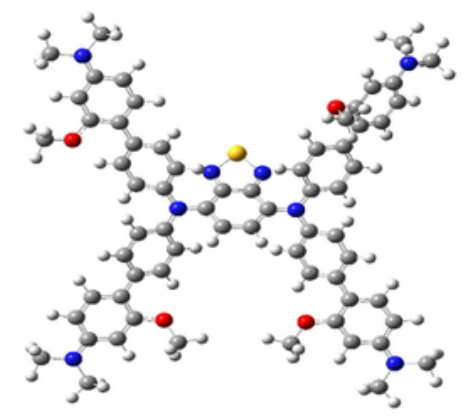

FD1

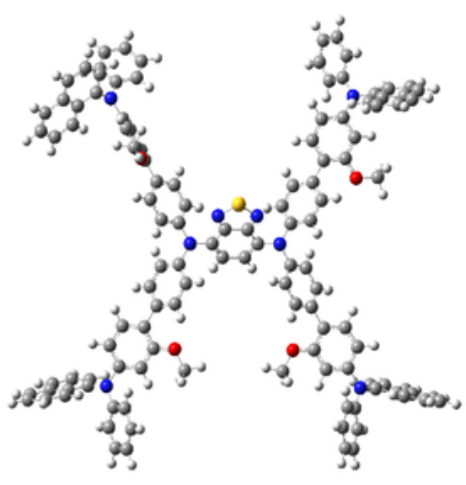

FD3

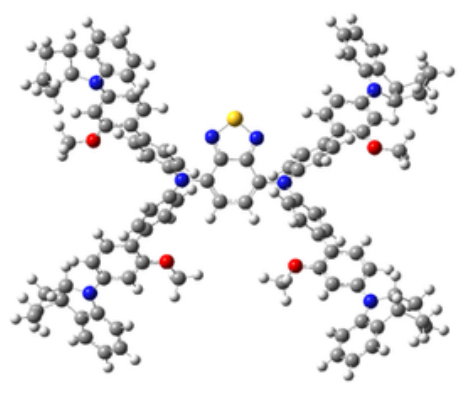

FD4

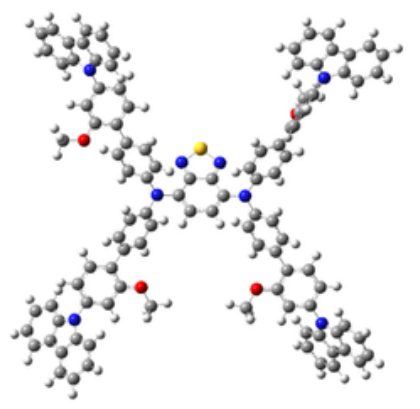

FD5

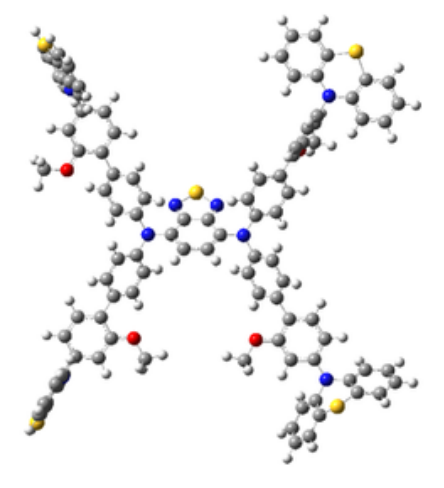

FD6

\section{Figure 3}

Optimize geometries of all studied molecules at Cam-B3LYP/6-31G $(d, p)$ basis set 


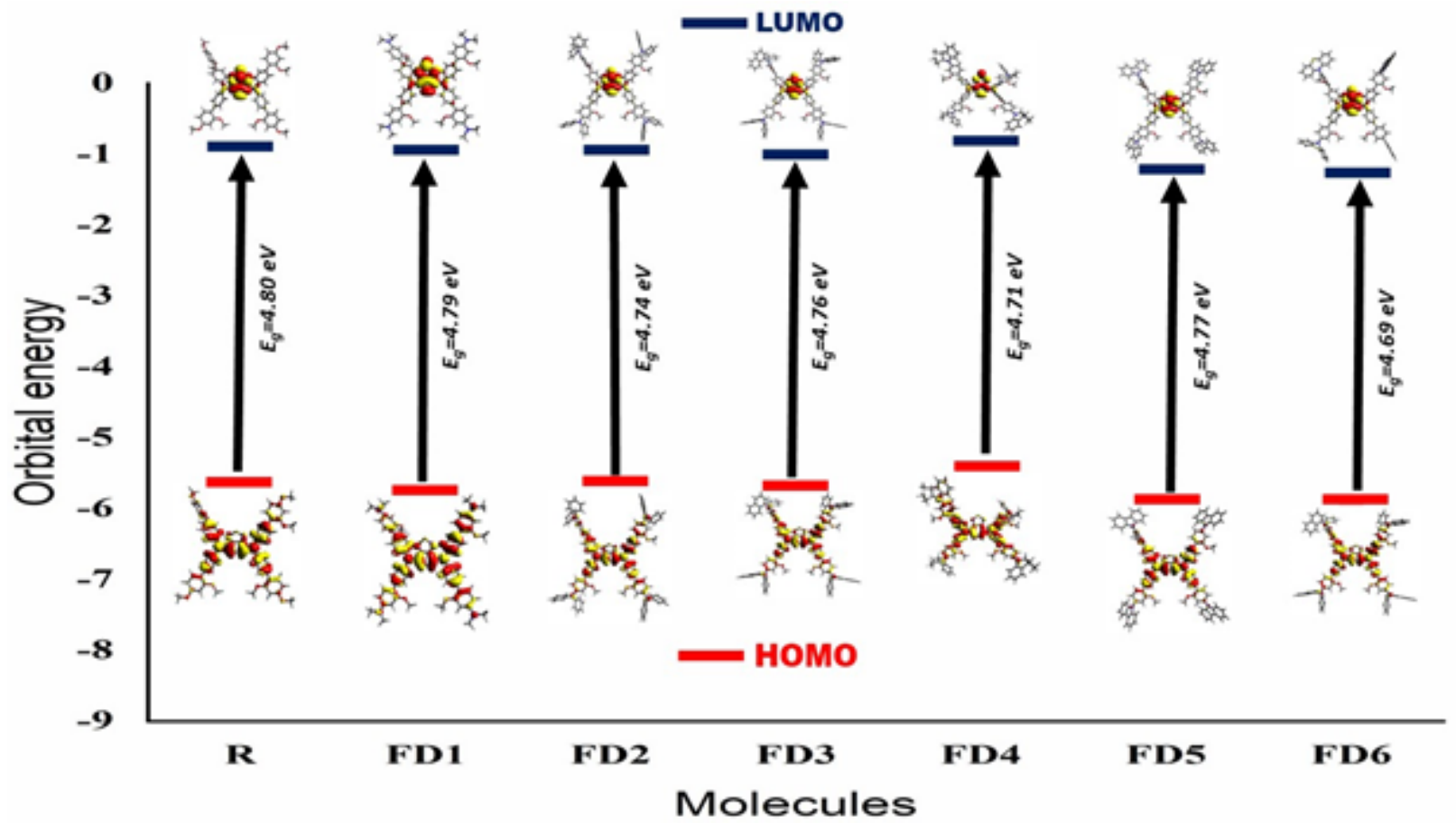

Figure 4

HOMO-LUMO energy gap and distribution pattern of frontier molecular orbitals on all studied molecules 

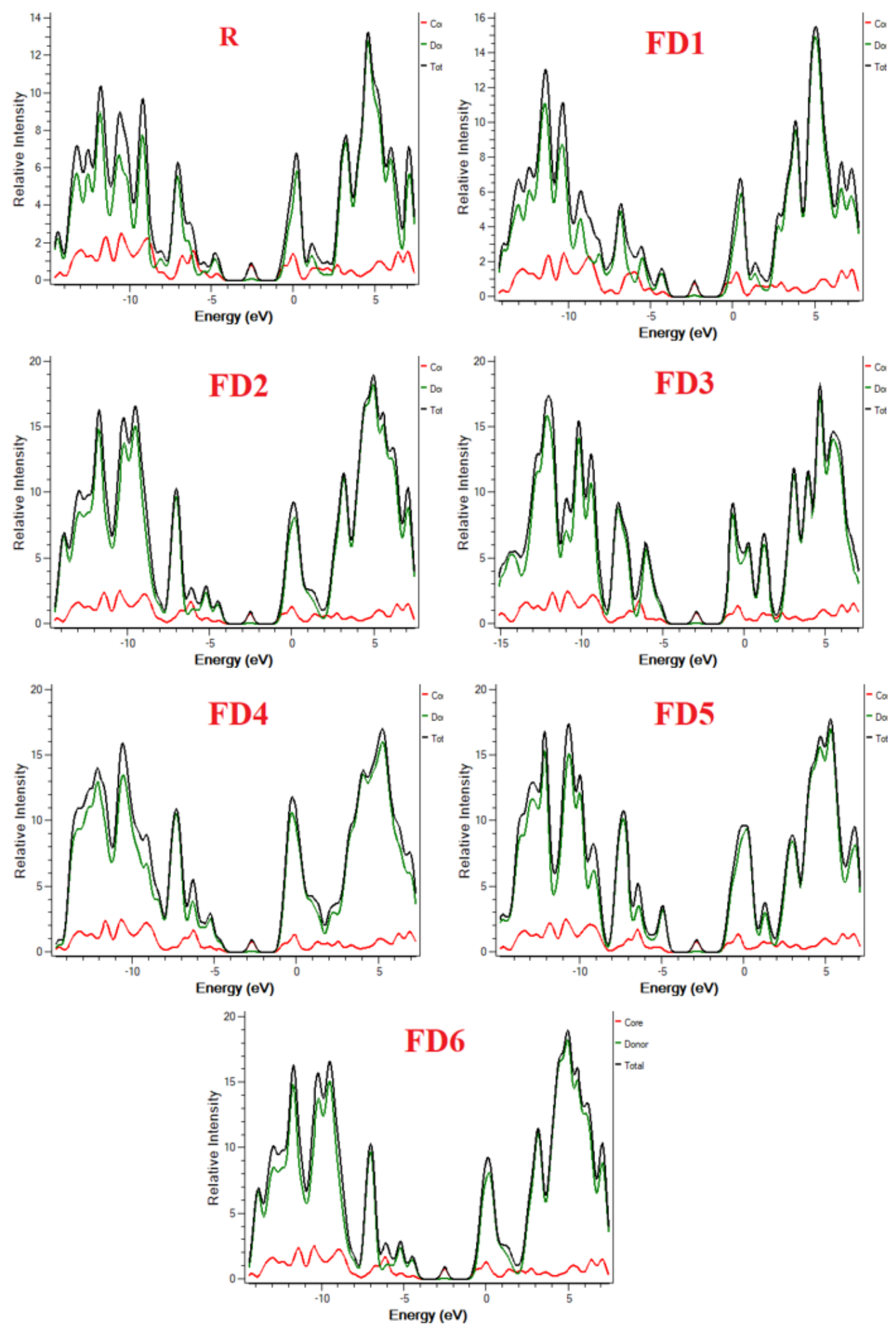

Figure 5

Density of states plots of all studied molecules 


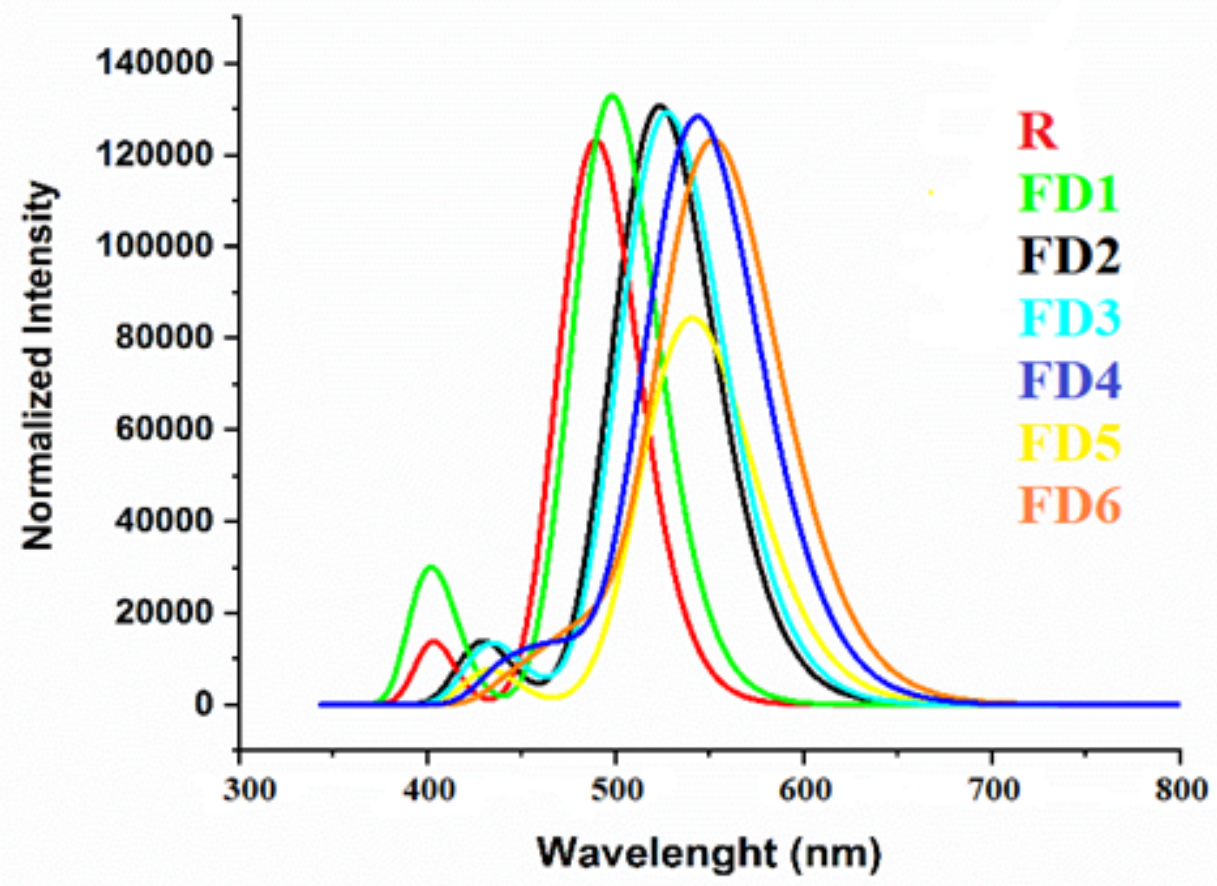

Figure 6

Simulated UV graph of all studied molecules in dichloromethane solvent.

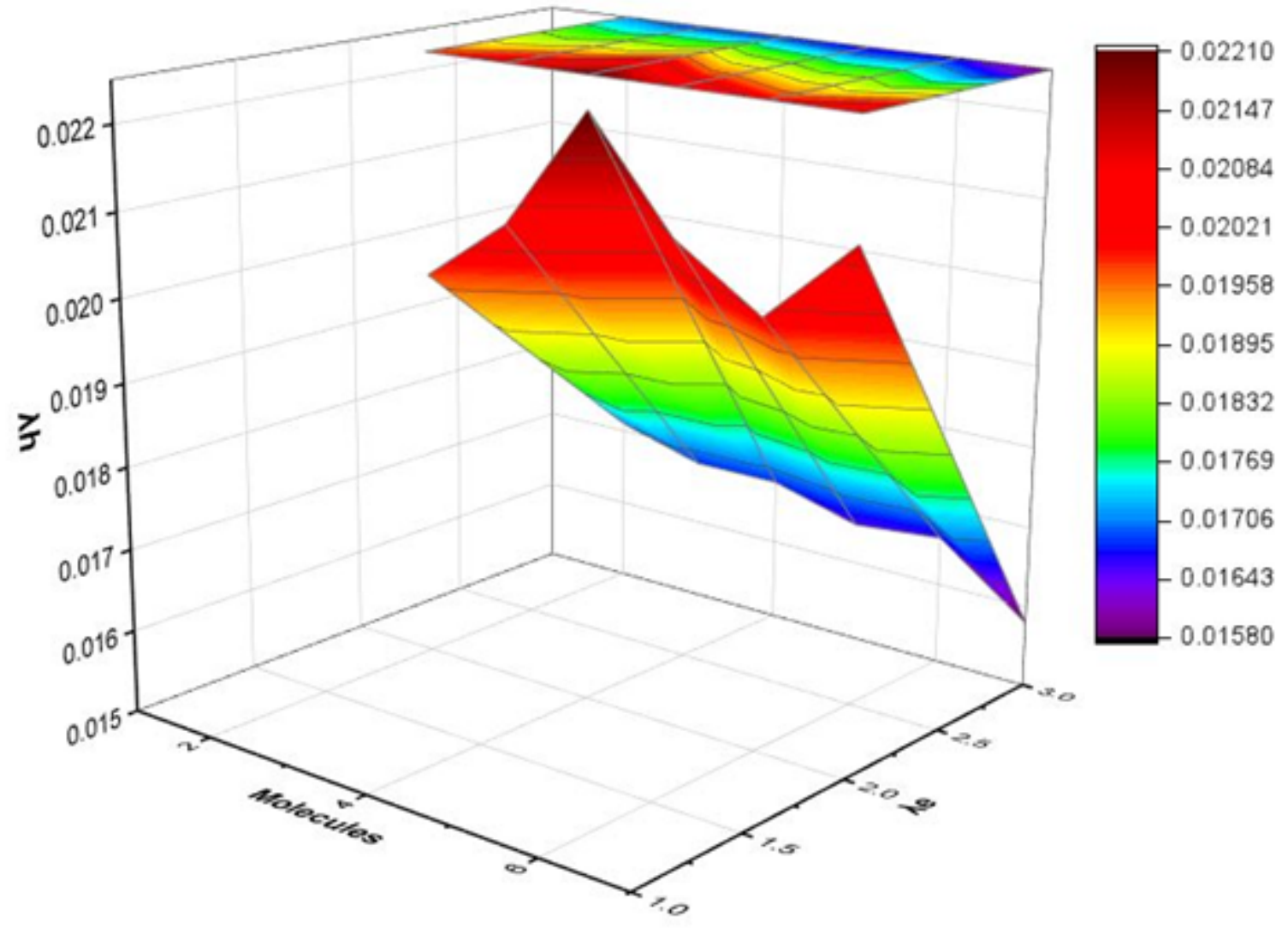

Figure 7 
Reorganizational energy of electron and hole of all studied molecules at Cam-B3LYP/6-31G(d,p)

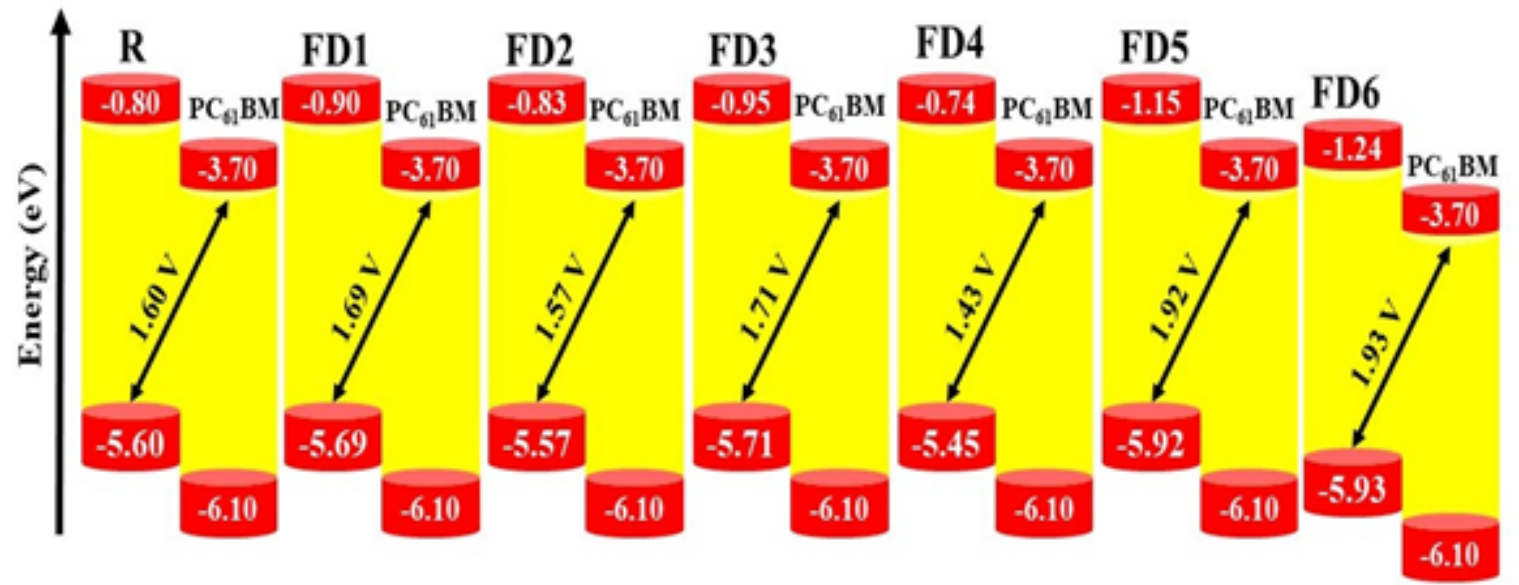

Figure 8

Open circuit voltage of all studied molecules at Cam-B3LYP/6-31G(d,p) basis set

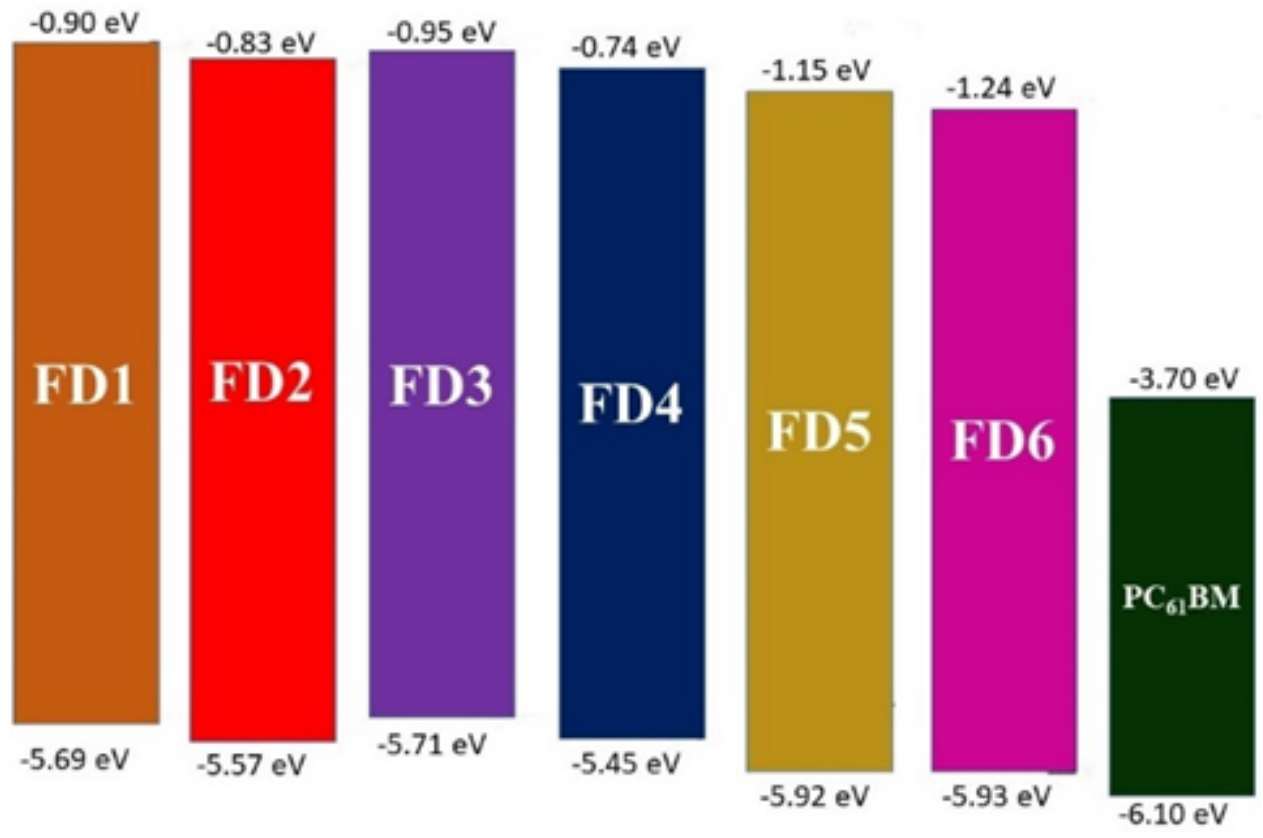

Figure 9

Orbital energy diagram of all donor molecules with respect to acceptor polymer 

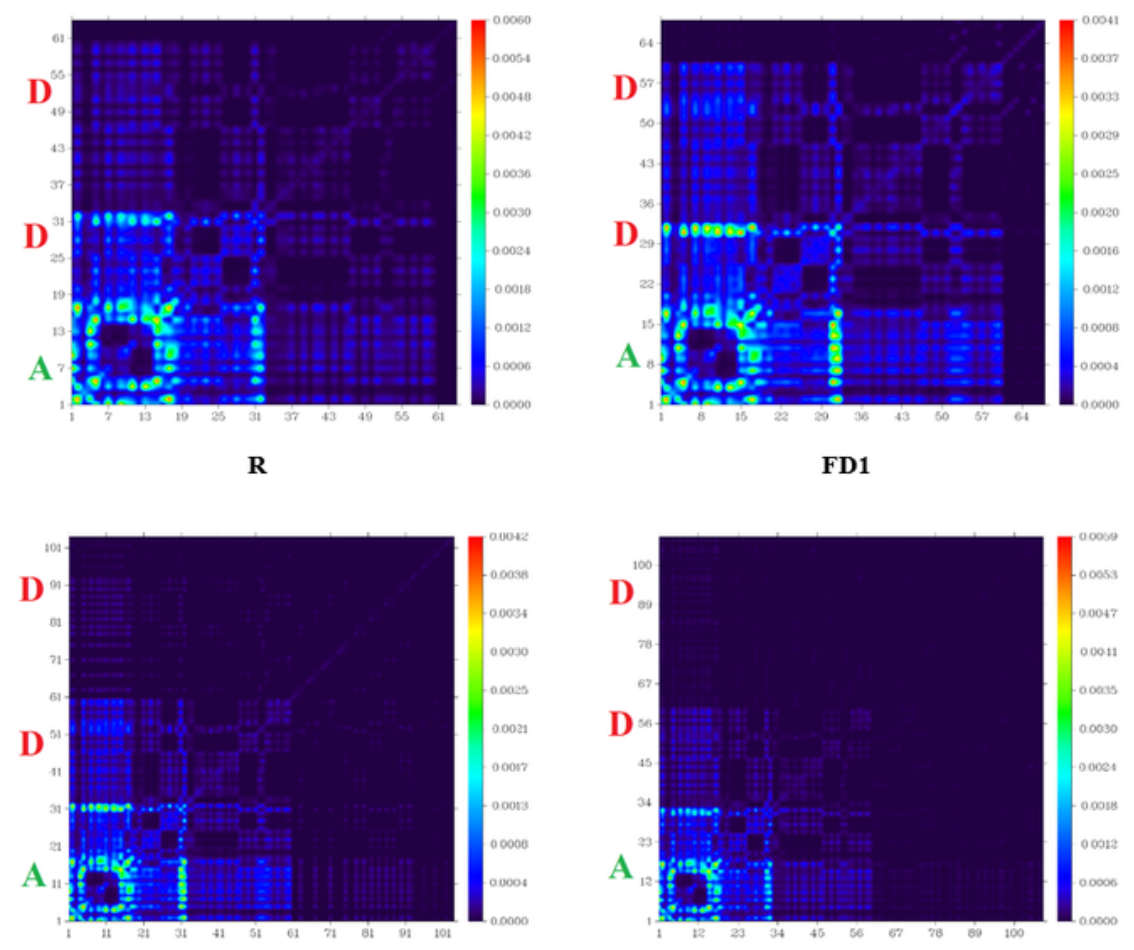

FD2

FD3

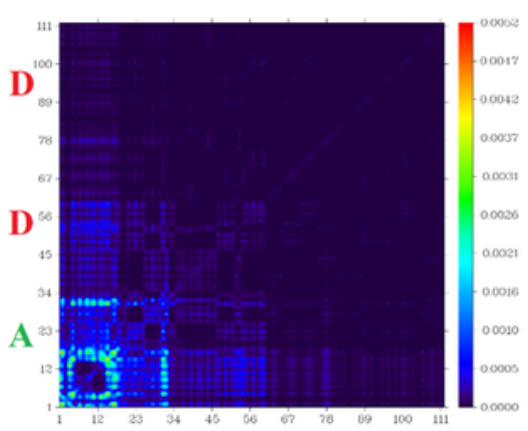

FD4
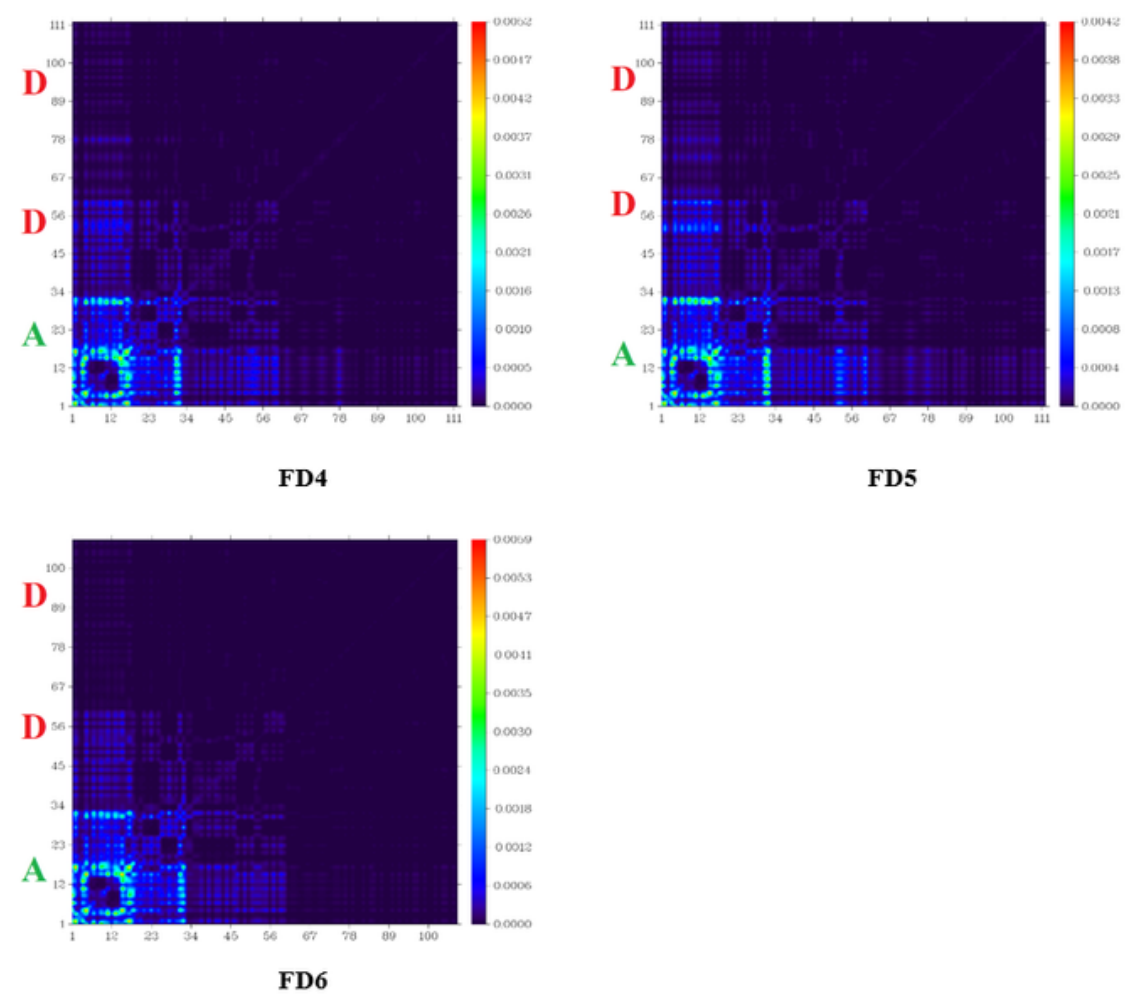

Figure 10

Transition density matrix plots of all studied molecules 


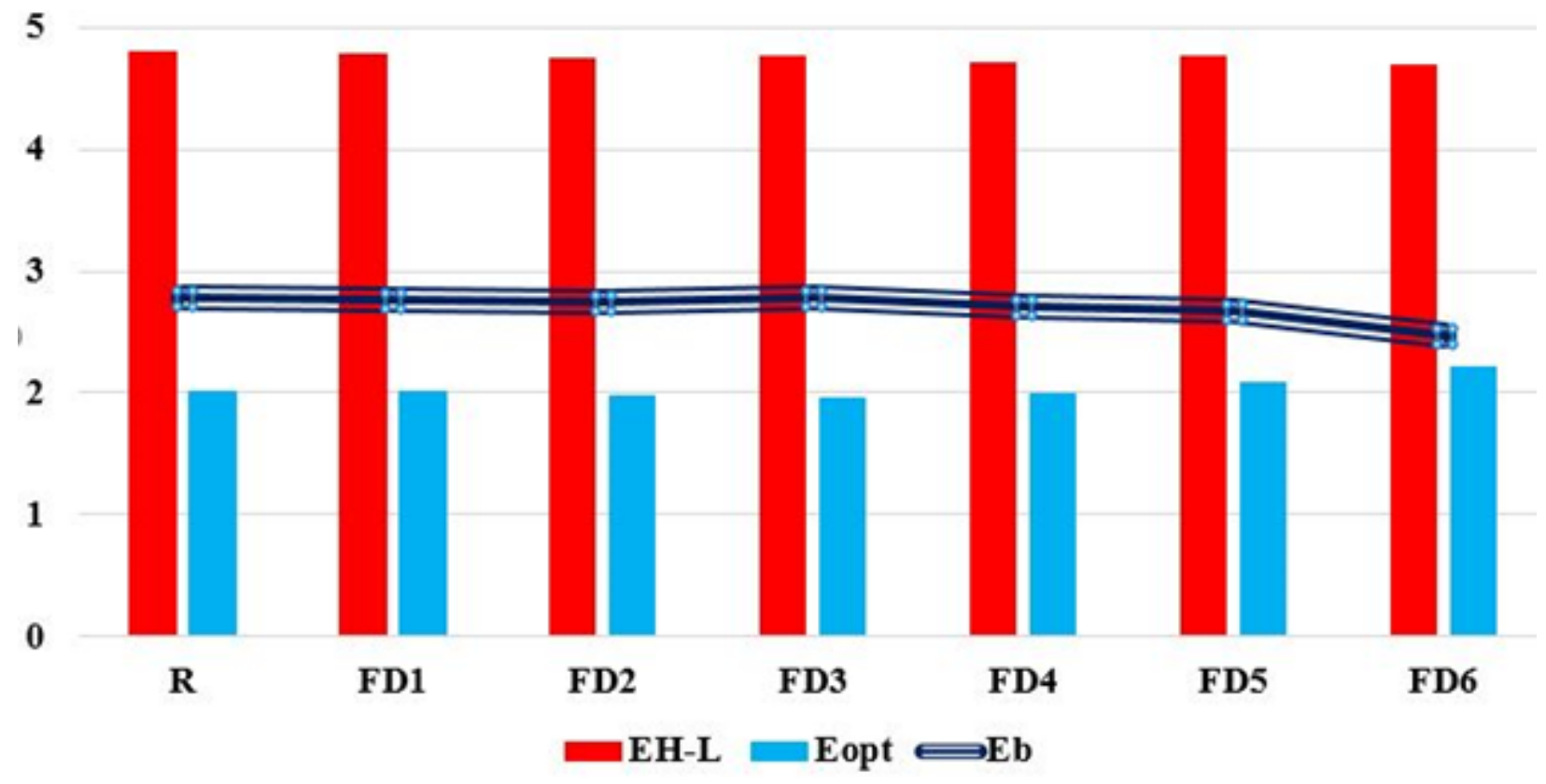

Figure 11

HOMO-LUMO gap, first principle excitation energy and binding energy of al studied molecules 


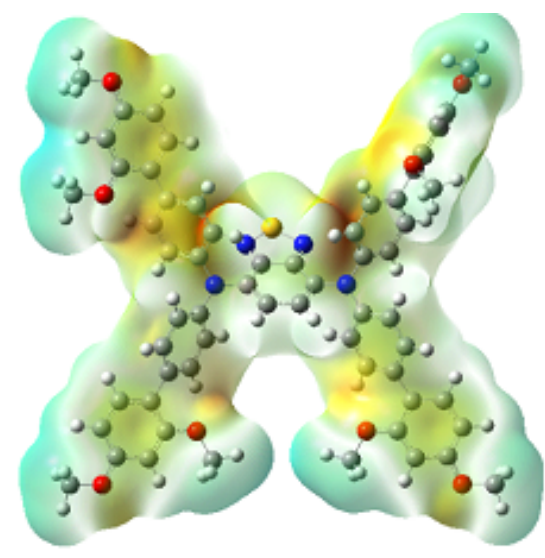

$\mathbf{R}$

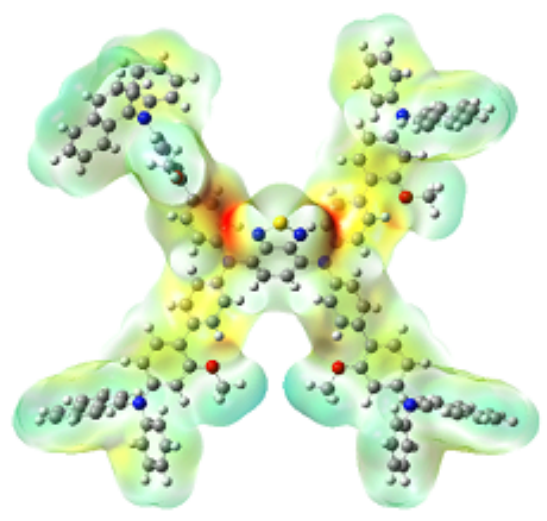

FD3

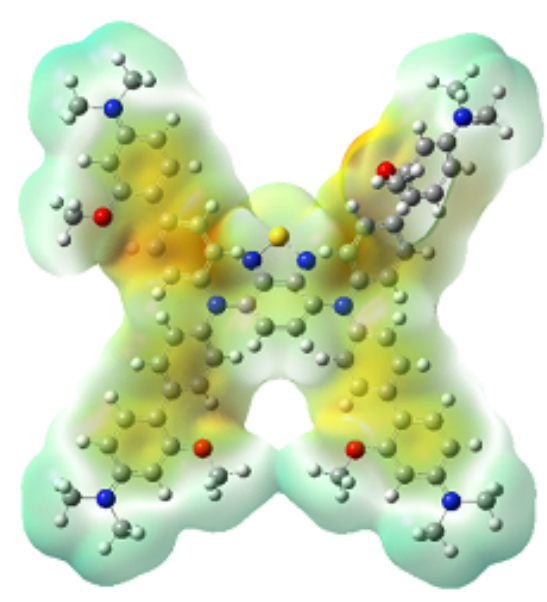

FD1

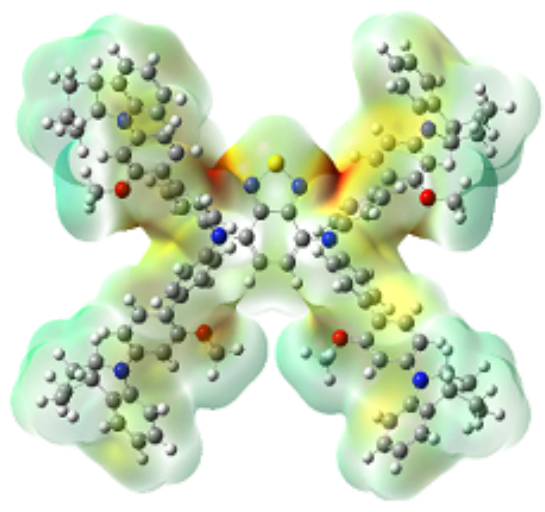

FD4

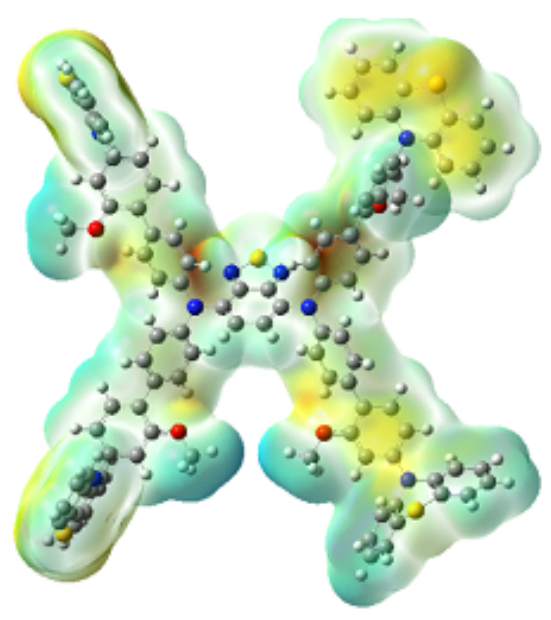

FD6

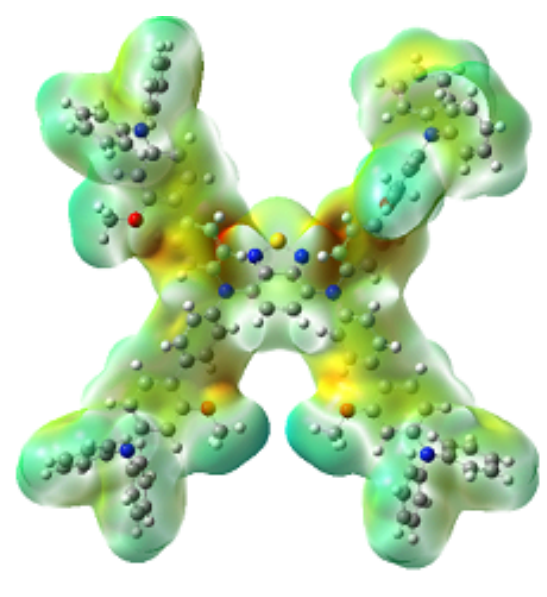

FD2

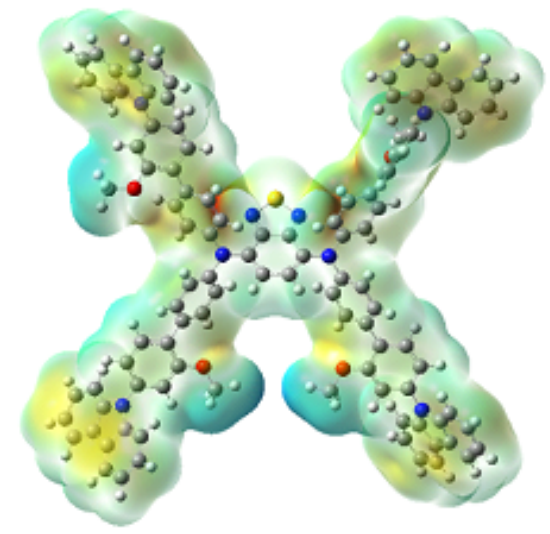

FD5

\section{Figure 12}

MEP plots of all studied molecules at $0.02 \mathrm{e} / \AA ̊ \AA 3$ iso-surface value 


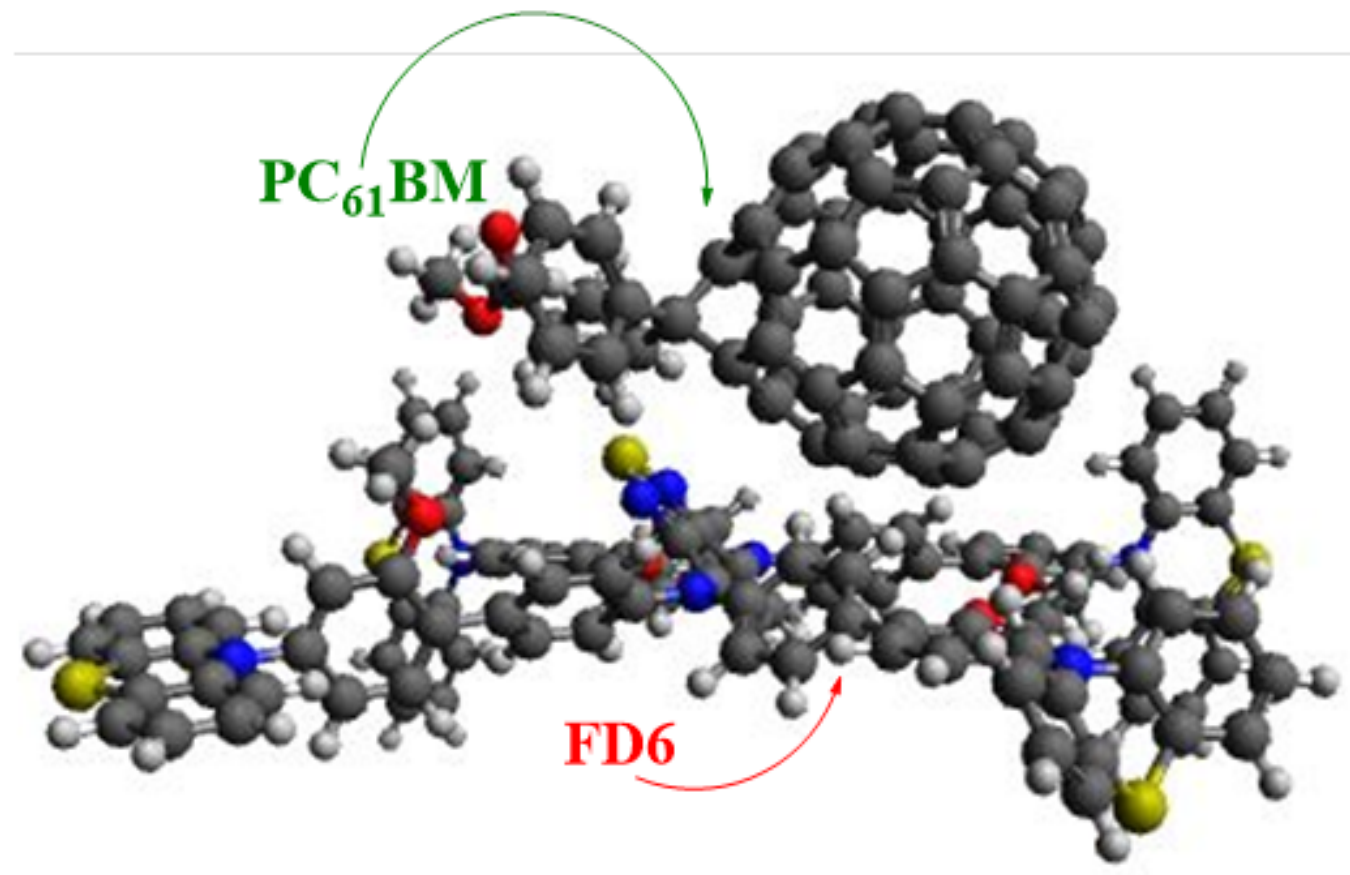

Figure 13

Optimized complex FD6:PC61BM at Cam-B3LYP/6-31G(d,p) basis set

HOMO

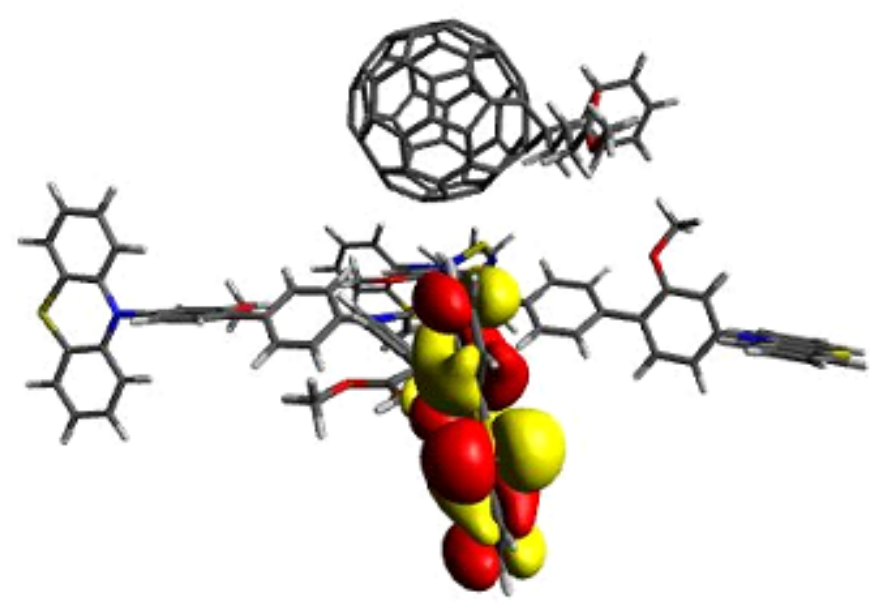

LUMO

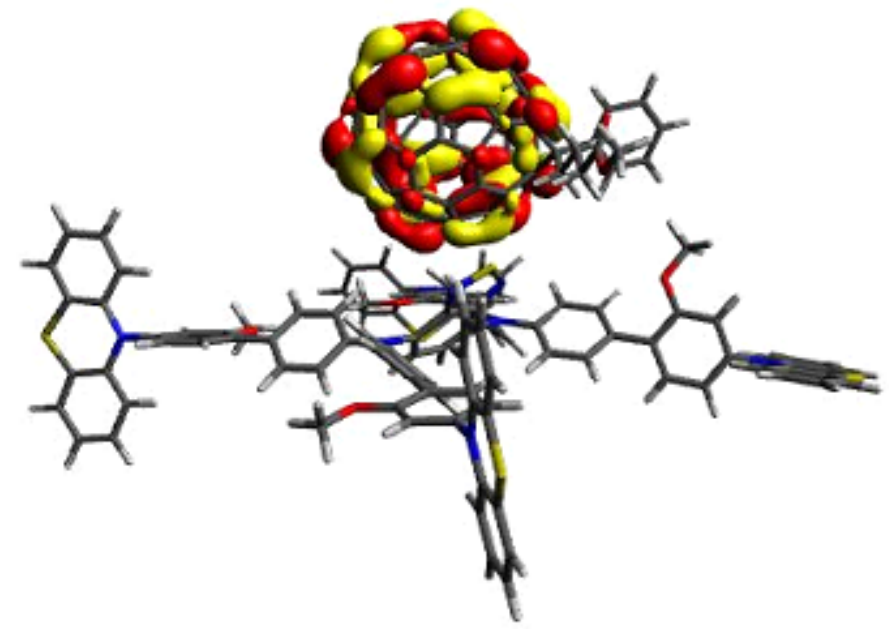

Figure 14

HOMO and LUMO of complex FD6:PC61BM at Cam-B3LYP/6-31G(d,p) basis set

\section{Supplementary Files}

This is a list of supplementary files associated with this preprint. Click to download.

- Supplementaryinformationfile.docx 
- floatimage1.jpeg

Page 27/27 